\title{
HOW TO DESIGN AND PLAN SUSTAINABLE SUPPLY CHAINS THROUGH OPTIMIZATION MODELS?*
}

\author{
Ana Paula Barbosa-Povoa**, Bruna Mota and Ana Carvalho
}

Received November 23, 2018 / Accepted November 23, 2018

\begin{abstract}
Sustainable Supply Chain is nowadays an increasing area of concern for both academia and industry that aims to design, plan and operate supply chains that guarantee market needs while considering not only profit objectives but also environmental and social concerns in a solution of compromise. Being supply chains complex systems the pursuing of such compromise solution calls for the use of decision tools that can support decision makers. Such tools should be based on quantitative models where Operational Research (OR) methods ought to be explored and where optimization, in particular, has a role to play. In this paper, the main characteristics of such optimization models, focusing on the design and planning of sustainable supply chains are discussed and the main issues to be considered when addressing such problems are identified. A framework, SusFrame, developed to guide practitioners and researchers in the development of optimization models for the design and planning of sustainable supply chains, is presented and applied to the solution of a set of case-studies, demonstrating the large applicability of such tool and how optimization methods can be used to help the sustainable supply chain decision process.
\end{abstract}

Keywords: sustainable supply chains, design and planning, optimization models.

\section{INTRODUCTION}

Supply chains play a vital role in companies' performance. With today's level of competitiveness, a strong, innovative product or service is not enough for a company to succeed. A carefully designed and planned supply chain is essential to ensure a service level that meets customers' expectations of a high quality, low cost product/service, and a fast, flexible and consistent delivery service (Christopher, 2012). But such problem is a challenging problem as globalization has increased the complexity of supply chain design with suppliers, plants, distribution centers and clients spread around the globe but needing to closely integrate its operations. Furthermore, the increasing societal concern with environment is pressing industry practitioners and policy

\footnotetext{
*Invited paper.

**Corresponding author.

Centro de Estudos de Gestão, Instituto Superior Técnico, Universidade de Lisboa, Av. Rovisco Pais, 1049-101 Lisboa, Portugal. E-mails: apovoa@tecnico.ulisboa.pt; bruna.mota@tecnico.ulisboa.pt; anacarvalho@ tecnico.ulisboa.pt
} 
makers to reduce the negative environmental impact of supply chains (Abbasi \& Nilsson, 2012). Thus, supply chains need to be managed considering not only economic, but also environmental and societal goals. Such concern is translated into the development of Sustainable Supply Chains (SSC), which is nowadays recognised as a challenging topic by both academics and companies not yet solved (Barbosa-Póvoa et al., 2018). The question on what grounds are supply chain decisions taken considering revenue related to social and environmental issues, are still to be answered. To respond to this question, amongst others related, there is a need for a clear understanding on how SSC have been addressed at the corporate level and what makes companies move towards sustainability (Carter \& Liane Easton, 2011). Earlier works on SSC characterization have appeared (Meckenstock et al., 2016) but much more has to be done so as to identify the main methodologies and drivers that companies should follow when trying to address SSCs (Barbosa-Povoa, 2014).

Additionally, SSC embrace fairly complex environmental, social and network systems. Challenges of dynamic markets and difficulty in controlling and managing uncertainties and tradeoffs amongst objectives are other examples of the complexity of this area. Thenceforth there is a great need for models that can support SSC decisions that consider the complexity involved, take holistic perspectives, and extend the weak assumptions underlying most of the published research (Barbosa-Póvoa et al., 2018). Recent reviews on modelling SSC has shown that some works have been appearing in the literature (Barbosa-Póvoa et al., 2018; Brandenburg et al., 2014; Seuring, 2013) but despite these valuable efforts research still has a long way to go, until a comprehensive methodology is in place, on which managers can draw when seeking decision support for SSC.

In order to support such decisions quantitative models, appear as powerful decision support tools to address supply chain complex problems since they allow a better understanding of the interactions, dynamics and trade-offs of the different variables involved (Cardoso et al., 2013; Dekker \& Fleischmann, 2004; Mota et al., 2015b, 2018; Salema et al., 2010). Furthermore, such models can be embedded in software systems so as to automate and optimize the described decisions.

In this paper, the main characteristics of such models that should be contemplated when designing and planning sustainable supply chain are presented and discussed. Sustainable supply chain characteristics are detailed and the problem description summarised. Both support the development of generic models where different constraint modules coupled with relevant objective functions are to be identified. The solution of two real supply chains will demonstrate the relevance of supporting decisions managers with quantitative models.

The remain of this paper is organized as follows. Section 2 presents the key concepts within sustainable supply chain, with a focus on design and planning optimization models where the main research gaps in the area are identified. Section 3 provides a sound framework to guide the development of generic optimization models for design and planning of sustainable supply chains. In section 4 a generic optimisation tool is presented and its main characteristics discussed. Section 5 presents the resolution of two case-study illustrating the applicability of the proposed framework and tool. Finally, in section 6 some conclusions are drawn. 


\section{SUSTAINABLE SUPPLY CHAIN DESIGN AND PLANNING: KEY CONCEPTS, METHODOLOGIES AND IDENTIFIED RESEARCH GAPS}

Governmental and societal concerns regarding sustainability issues have been pressuring industries to re-evaluate their supply chains (SC). Supply chain management has evolved across the years, differing the type of structure considered by the companies. The traditional SC is the forward SC, where the flow of materials come from suppliers to consumers. Then the concept of reverse SC has appeared with the flow of materials coming from consumers to suppliers, whose main goal is to efficiently and effectively plan, implement and control the surplus or unwanted materials and related information by either recapturing value (recycle, reuse, repair, refurbish and remanufacture), or proceeding to a proper disposal (Sarkis et al., 2010). Combining the two previous SCs, appears the concept of the Closed-loop SC, which addresses both product supply and return process issues. Here the recovered products can either re-enter the forward chain, or be taken to a secondary market, via a reverse chain (Salema et al., 2010). As sustainability arises has a main society driver, from an inter-emotional philosophical point of view, this concept involves meeting "the needs of the present generation without compromising future generations", according to Brundtland's report (WCED, 1987). Therefore SCs have evolved to incorporate the Sustainable Supply Chain (SSC) perspective. These SCs can be described as complex network systems that involve diverse entities that manage the products from suppliers to customers and their associated returns, accounting for social, environmental and economic impacts (BarbosaPóvoa, 2014). SSC further extend the concept of CLSC, integrating the three pillars of sustainability. The complexity involved in having different and, in some cases, opposing objectives in addition to the already complex supply chain design and planning problem has defined SSCs as a very current research path (Barbosa-Póvoa et al. 2018).

Therefore it is important to analyse what has been done in the past years regarding SC, where the economic pillar has prevailed as the main objective, and the integration of the environmental and social pillars towards the creation of a SSC has been augmented.

The first step towards sustainable supply chains was performed with the works on closed-loop supply chains. This was recognised in the review by Fleischmann et al. (1997) and explored later on in the work of Fleischmann et al. (1997), which study the impact of product recovery on supply chain design decisions and conclude that the influence of product recovery on supply chain decisions is very much context dependent. While in some cases product recovery can be integrated in logistics structures, in others it may require redesigning the network. Salema et al. (2007) builds on this model and incorporates capacity limits and uncertainty on demand and return in a multi-product formulation. Cardoso et al. (2013) study the integration of reverse logistics activities under demand uncertainty, considering the expected net present value maximization as the objective function and modelling decisions on sizing and location of facilities, installation of processes, forward and reverse flows, as well as inventory levels. Literature is also available on closed-loop supply chain models that integrate environmental objectives, in addition to the economic ones. Paksoy et al. (2011) considering emissions costs in the economic objective function (total cost minimization) as well as profit from recycled products maximization. 
Chaabane et al. (2012) explicitly include an environmental objective function, which minimizes global warming potential, thus minimizing carbon emissions. Total logistics costs measure the economic performance of the supply chain. Decisions analyzed include carbon management, namely carbon credits purchase or sale. Mota et al. (2015) propose a closed-loop supply chain multi-objective model which integrates the three pillars of sustainability: the economic pillar is assessed through supply chain costs, the environmental pillar is assessed by applying ReCiPe LCA method to transportation and entity installation activities, and the social pillar is assessed through a developed indicator related with population density. Mota et al. (2018) evolve the preceeding work to obtain a generic multi-objective model for the design and planning of sustainable supply chains which integrates several strategic and tactical decisions such as supplier selection and supply planning, facility location-allocation, distribution network definition, manufacturing technology selection and production planning, and product recovery strategy definition. Demand uncertainty is also addressed.

From the literature review on this subject although an evolving trend towards sustainable supply chains has being observed the following main research gaps still exist:

- The need for a more integrated framework that incorporates issues other than locationallocation such as operational decisions (such as production planning and inventory decisions), tactical (such as network flows) and strategic ones (such as facility location and capacity determination, as well as technology decisions) (Govindan et al., 2015; Ilgin \& Gupta, 2010);

- The need for closed-loop supply chain models that explicitly deal with the environmental impacts (Barbosa-Póvoa et al., 2018; Dekker et al., 2012). The authors state that simply closing the loop does not guaranty a reduction in the supply chain's environmental impact;

- The need for models that explicitly assess the impact of supply chains on people or society, integrating the social pillar of sustainability (Barbosa-Póvoa et al., 2018; Tang \& Zhou, 2012);

- The need for multi-objective decision making that includes appropriate environmental and social objectives (Barbosa-Póvoa et al., 2018; Govindan et al., 2015).

As environmental and social objectives are the least objectives studied within supply chains is important to understand how these have been treated along the years.

\subsection{Environmental Assessment}

Consumers are now more concerned with the ecological behaviour of the products they purchase, as well as governments have been approving legislation that presses companies to go green. Research has shown that environmental performance can generally have very little impact on financial performance (Elsayed \& Paton, 2005). Hence, most company managers are realizing that taking the lead in ecological behaviour could bring them important benefits (Nidumolu et al., 
2009). Company managers are also realizing that it is necessary to look beyond the company's core business to achieve environmental improvements and, ideally, sustainability. An analysis of the entire supply chain in an integrated perspective is needed, and choices such as selecting suppliers or distribution channels make a difference (Gold et al., 2010).

LCA has been described as the most scientifically reliable method currently available for studying and evaluating the environmental impacts of a certain product or process, allowing both retrospective and prospective assessment (Carvalho et al., 2014). Hence, this methodology has been and continues being used for supply chain design and planning (Barbosa-Póvoa et al., 2018). Many different methods have been developed to assess environmental impact, from cradle to grave, which means from suppliers to disposal. All of them presenting advantages and disadvantages (European Commission, 2010). Hugo \& Pistikopoulos (2005) developed a mathematical programming-based methodology where LCA is included as criteria for the strategic investment decisions related to the design and planning of supply chain networks. Eco-indicator 99 is used to assess the environmental impact and this is balanced with the economic criteria through a multi-objective approach. Guillén-Gosálbez \& Grossmann (2009) addressed the design of sustainable supply chains in the presence of uncertainty in the life cycle inventory associated with the network operation. A bi-criterion stochastic mixed-integer nonlinear program simultaneously accounts for the maximization of the net present value and the minimization of the environmental impact, measured through Eco-indicator 99, for a given probability level. Duque et al. (2010) developed a mixed-integer linear program, which is able to suggest the optimal processing and transportation routes, while optimizing a given objective function that either meets the design and environmental constraints or minimizes the environmental impact, measured (also) using Eco-indicator 99. Again, a multi-objective approach is implemented through the use of the $\varepsilon$-constraint method. This model also offers the possibility of inclusion of the environmental costs into the economic function, whenever the impacts/damages costs are quantifiable. This is desirable as it makes the results more comprehensible, however these numbers are rarely available. In fact, Eco-indicator 99 is one of the most used methodologies though it presents the disadvantage of only providing information at the endpoint level as well as of not having comprehensible units which hinders results analysis. More information on the available environmental impact assessment methodologies can be seen in the ILCD Handbook (European Commission, 2010). More recently, Pinto-Varela et al. (2011) addressed the planning and design of supply chain structures for annual profit maximization, while considering environmental aspects, accounted also through Eco-indicator 99. The supply chain is modelled as a mixed integer linear programming optimization problem, this time using the Resource-Task-Network (RTN) methodology. The model allows for the selection of the different entities presented within a generic supply chain such as production facilities, warehouse and distribution centers. Furthermore, for all location sites the types of technological resources used are also determined. Profit and environmental impacts are balanced using an optimization approach adapted from symmetric fuzzy linear programming. Bojarski et al. (2009) also address the optimization of supply chain planning and design considering economic and environmental issues. It considers facility location, processing technology selection and production-distribution planning. The environmental impact is this 
time assessed through IMPACT 2002+, which allows using both midpoint and damage categories. A multi-objective approach is also applied, and the criteria used for the objective function are damage categories impacts, overall impact factor and net present value.

According to JRC (European Commission, 2011), ReCiPe 2008 proposed by Goedkoop et al. (2009) is the most developed methodology so far. It is a follow up of Eco-indicator 99 and CML 2002, presenting both midpoint and endpoint categories. PEF (Product Environmental Footprint) is another LCIA method, recently released by the European Commission with the goal of achieving standardization amongst the pre-existent life cycle approaches (European Commission, 2013).

From the literature review the main research gaps were identified:

- Inexistence of a general accepted method to evaluate environmental impacts through LCA;

- Despite some authors have included in their mathematical models the environmental assessment, there is a lack of optimization models, which apply the most accepted and recent LCA methods, such as ReCiPe and PEF.

\subsection{Social Assessment}

The social pillar of sustainability has unquestionably been the least addressed pillar in sustainable supply chain design and planning (Barbosa-Póvoa et al., 2018), given the difficulty in addressing such complex and most of the times subjective issue. However, its inclusion in supply chain decisions is compulsory, as ignoring it may have negative consequences to the companies involved in the supply chain. Although a given technology may be economically and environmentally beneficial it will not most likely be socially beneficial. Like in the case-study presented by Hunkeler (2006), having a product with less costs and less environmental impact usually means it contains less components. Even though for the company this might not be a problem in terms of social impact, having less components to be produced means that the supplier of these components will reduce production, which will ultimately lead to the dismissal of employees. And, if this is not handled correctly, it can lead to the loss of confidence from the employees, to a decrease in productivity and eventually to the degradation of the brand. This is a small example on why it is necessary to consider the entire supply chain and also the entire life cycle of the products when assessing social performance.

Social Life Cycle Assessment (SLCA) is a tool that is currently under development to address these issues and to help stakeholders to effectively and efficiently engage to improve social and socio-economic conditions of production and consumption (UNEP-SETAC, 2009). It is a tool similar to Environmental Life Cycle Assessment however it is not nearly as developed as the latter (Jørgensen et al., 2008). Benoît et al. (2010) offers a brief summary of the works developed so far. Some frameworks have been proposed for SLCA such as the one from Dreyer et al. (2006), which consisted of two layers of impact categories, an obligatory, addressing social impacts relevant for all companies, and an optional, justified by the observation that many 
important social impacts of companies will be dependent on the specific business context. Hunkeler (2006) developed an interesting methodology for societal life cycle assessment, based on an existing Life Cycle Inventory (LCI). This methodology uses labour hours for units, and it was tested on an existing LCA-detergent case. The trade-offs with the environmental impact were also discussed. Hutchins \& Sutherland (2008) reviews metrics, indicators and frameworks of social impacts, and initiatives relative to their ability to evaluate the supply chains social sustainability. It also proposes quantifiable indicators that, even though not covering all dimensions of social sustainability, can be used in decision-making related to supply chains. Since the release of the Guidelines for Social Impact Assessment of Products (UNEP-SETAC, 2009), more case-studies have emerged, as the one by Ciroth \& Franze (2011). However, the majority of these works come across the same problems, which are the lack of data and the difficulty of adding up/joining the results of different social indicators (Labuschagne et al., 2005).

The GRI Guidelines are another important tool. The Global Reporting Initiative (GRI) is a nonprofit organization that promotes economic, environmental and social sustainability. It provides all companies and organizations with a comprehensive sustainability reporting framework that is widely used around the world. Jorgensen et al. (2008) created some generalized impact categories inspired in the Global Reporting Initiative and characterized different SLCA approaches according to these categories. However, most of these indicators are based on passed occurrences or in some other way do not quite fit into supply chain design and planning context.

From the literature review the main research gaps regarding the social analysis were identified:

- Lack of standardized and accepted indicators to assess strategic decisions in supply chains;

- Lack of integration of the social assessment in optimization models.

Summarizing, it is possible to verify that mathematical models covering a holistic perspective on SSC are still missing in the literature. Moreover, the few attempts that some authors have made are limited views of the SSC, without a good environmental assessment and without incorporating social aspects, so that sustainability can be accomplished. Thus, there is a need of creating a generic framework that will support the development of quantitative models for the construction of SSC. This will be explored in the next sections.

\section{A FRAMEWORK FOR THE DEVELOPMENT OF SUSTAINABLE SUPPLY CHAIN OPTIMIZATION MODELS}

This section presents a generic framework, SusFrame, developed to guide practitioners and/or researchers in the development of optimization models for the design and planning of sustainable supply chains. As seen in Figure 1, the optimization model structure is aligned with questions designed to support the construction of the model. The possible approaches are provided as well as examples to better understand each of them. 


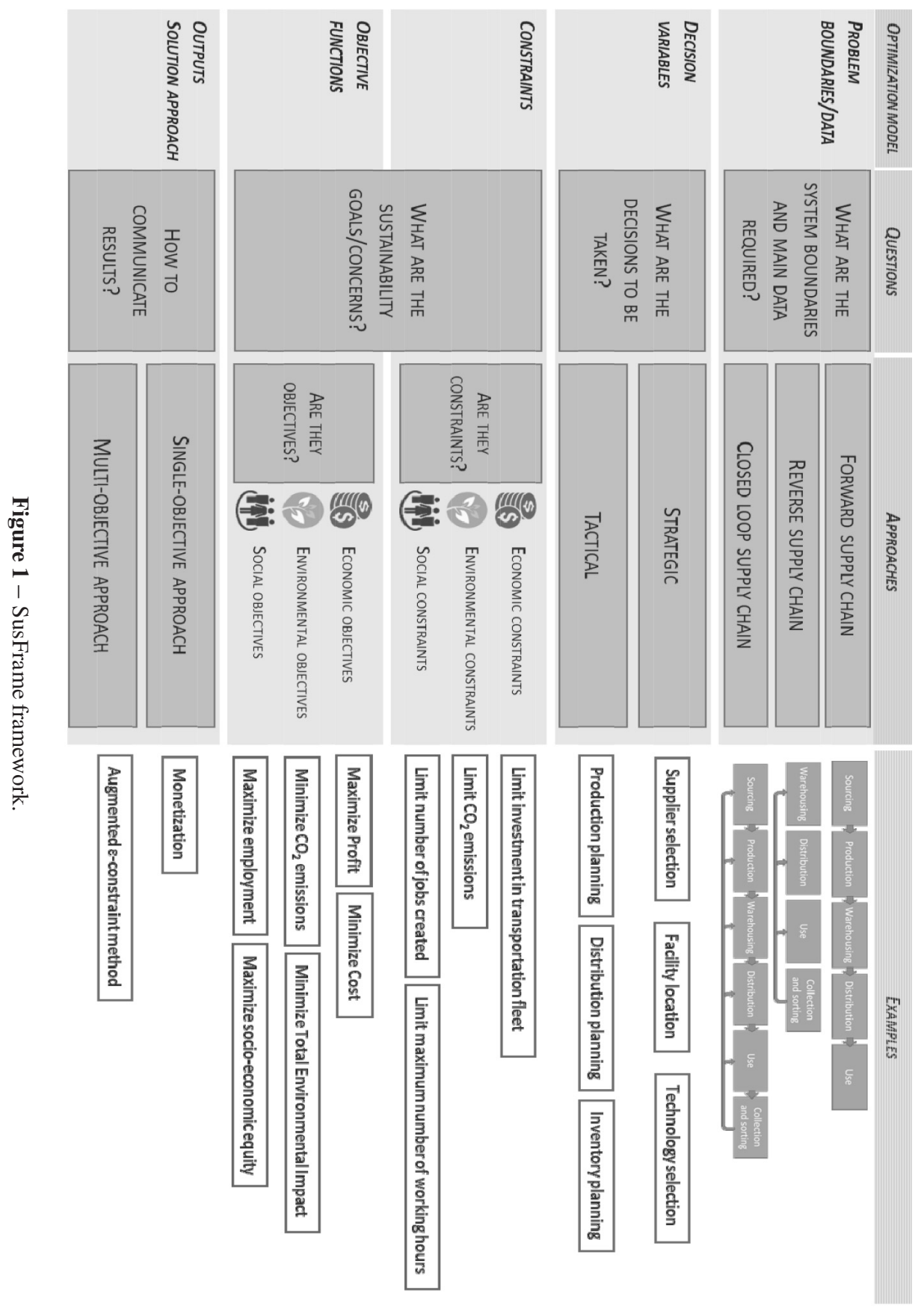




\subsection{Problem Boundaries/Data}

The first step should be the definition of the objectives and scope of the work. This definition can begin with the question: What are the system boundaries? The possible approaches suggested help limit such boundaries considering the flows of products:

- Forward supply chain: in which only the flow of products towards the consumer is considered;

- Reverse supply chain: in which only the reverse flow of products, that is, the flow of end-of-life products is considered;

- Closed-loop supply chain: in which both forward and reverse flows are considered simultaneously.

Another important consideration in this step is the availability of data to support this boundary definition and hence the question: What are the main data required? When defining the system boundaries, it is important to assure that there is data available to support the evaluation of the economic, environmental and social performances equally. This also means including the supply chain activities in the objective functions, to the extent possible. This approach supports a holistic view of the supply chain processes, so as to guarantee that all sustainability pillars are being equally evaluated.

\subsection{Decision variables}

The second question (What are the decisions to be taken?) allows the definition of the supply chain activities that are object of decision. These can be strategic and/or tactical decisions. Figure 2 depicts possible supply chain decisions to include, which need to be aligned with the previously defined boundaries. The integration of the different supply chain activities, being evaluated simultaneously, has been proven to provide better overall results, as will be discussed in section 5.2.

\subsection{Constraints and objective functions}

The third question (What are the sustainability goals/concerns?) is used to define the supply chain sustainability goals and concerns to include in the optimization model. These can be included in two ways:

- As constraints, which can occur due to legal compliance issues (e.g. limiting the number of working hours), internal policy practices (e.g. limiting the $\mathrm{CO}_{2}$ emissions of the supply chain) or a manifested desire by the decision makers (e.g. limiting the investment in the transportation fleet); 


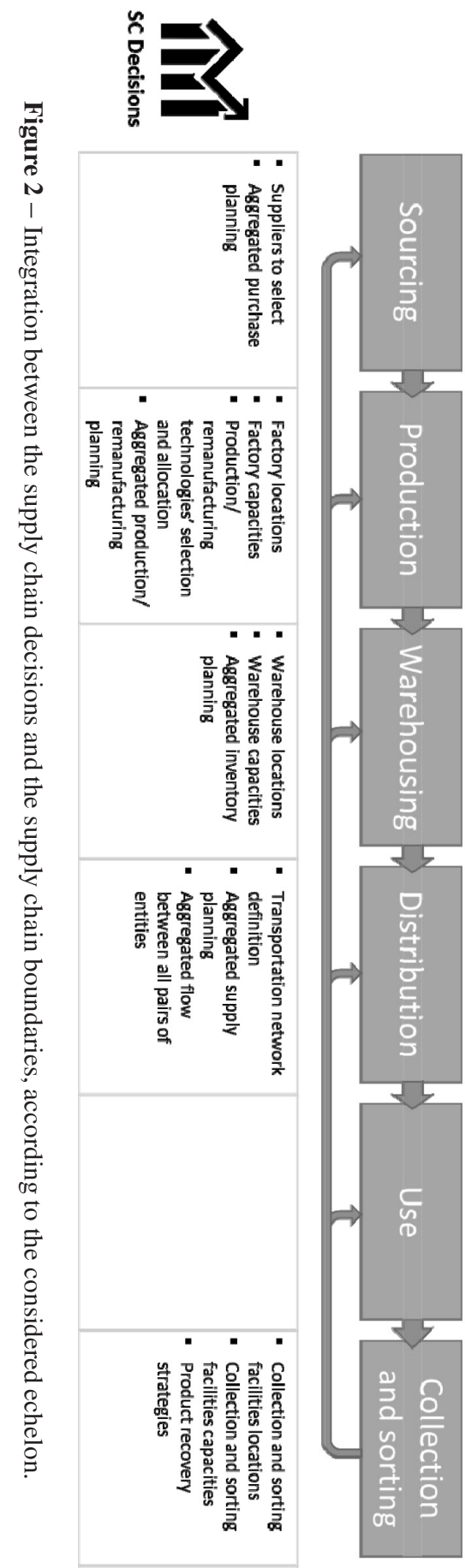

Pesquisa Operacional, Vol. 38(3), 2018 
- As objective functions, in which the goal might be simply to reduce total supply chain costs or maximize profit (in which case a single objective function is considered), or to go beyond that to also take into consideration the two other sustainability pillars (in which case an objective function is added per sustainability pillar or considered goal). Regarding the environmental pillar different LCA methods can be considered, being ReCiPe and PEF the most recommended ones, as explained before. These methods provide a more holistic approach on the environmental impacts of the supply chain, considering different environmental impact categories such as climate change, natural land transformation, water depletion, etc. An alternative, often easier due to data availability, is to focus on a single impact category. Typically the environmental component is focused on the quantification of $\mathrm{CO}_{2}$ emissions. However, this approach can result in a set of supply chain decisions that provides better results in terms of $\mathrm{CO}_{2}$ emissions, but worse results for other environmental impact categories. Regarding the social sustainability pillar, the most used indicator in strategic-tactical decisions is the number of jobs created. SusFrame couples this decision with the goal of socio-economic equity, that is, the goal becomes to maximize the number of jobs created in regions/countries where, for example, the unemployment rate is higher. The socio-economic indicator used should be adjusted to the system boundaries, as will be demonstrated in the two case-studies to be presented.

\subsection{Outputs/solution approach}

Gathering the results obtained for each of the objective functions, the most likely is that quite different solutions will be obtained. The question then becomes: how to communicate the results to the decision maker? Different options exist and SusFrame allows exploring them. One relates to the option of translating all objective functions into the same monetary units, the so called monetization of impacts. While this can be done for the environmental objective function, through methods such as EPS, for the social objective function no method is yet available. Another option, explored in one of the presented case-studies, is related with a multi-objective approach where the $\varepsilon$-constraint method is used to obtain a set of efficient solutions that represent compromise solutions. This option allows to visualize the trade-offs between the three pillars of sustainability.

\section{A GENERIC OPTIMIZATION MODEL FOR THE DESIGN AND PLANNING SUSTAINABLE SUPPLY CHAINS - TOBLOOM}

Having defined the framework, SusFrame, the goal is to translate such concepts into a generic modelling tool. ToBLoOM, a developed optimization-based tool, is in line with this concern and its overall goal is to determine simultaneously the supply chain network and the associated planning decisions, while assuring a solution of compromise that accounts for the three sustainability objectives: economic, environmental and social (Mota et al., 2018). This tool can deal with different supply chain structures and characteristics as represented in Figure 1. The supply chain considers four main supply echelons: suppliers; production; warehousing; costumers. Forward and reverse flows are accounted for in this structure and different transportation modes 
may be used. At each entity, different processing and/or storage technologies may be installed, which differ on cost and efficiency and may have different environmental and social associated impacts. Remanufacturing technologies at both production and warehousing facilities may also be installed, so as to process the flows of products that may receive from the costumers.

As mentioned such tool is supported by an optimization model, which using the supply chain set of data translating the supply chain main characteristics is able to determine the main strategic and tactical supply chain decisions regarding the supply chain network and related usage of resources (planning decisions). This model, thoroughly described in Mota et al. (2018), has been applied to several case-studies, two of which are described in this work, so as to exemplify real applications of SusFrame.
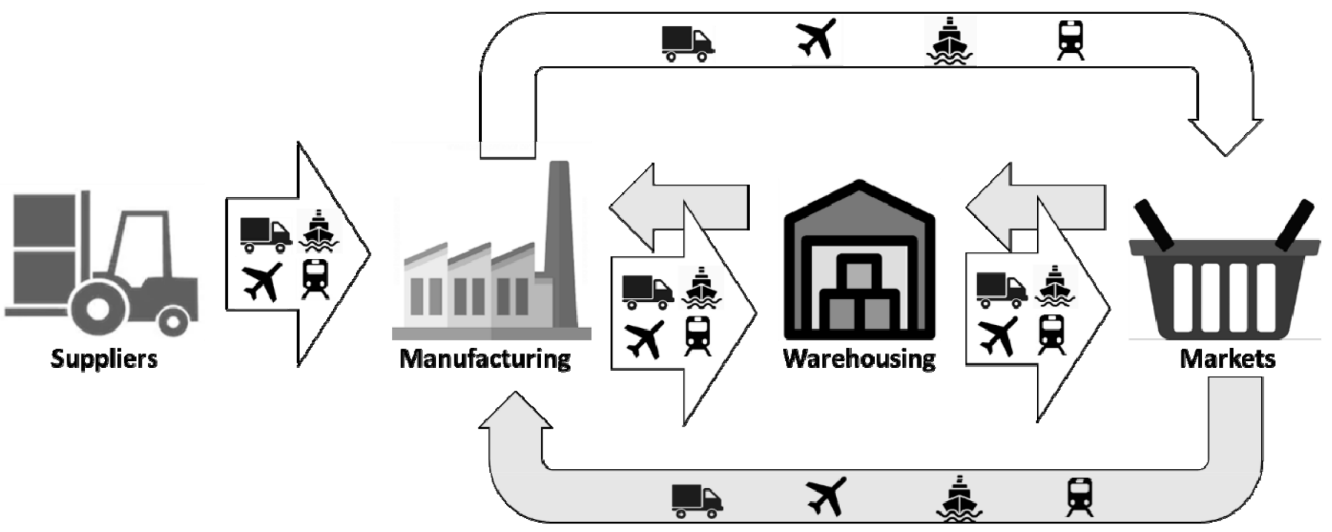

Figure 3 - ToBLoOM Generic Supply Chain Network.

\section{CASE STUDIES}

In this section, two case-studies are presented, which highlight the different aspects and challenges presented before, and describe real case applications of SusFrame and ToBLoOM. As shown in Table 1, the first case-study is based on a food retail supply chain, considering the forward supply chain.

The minimization of supply chain cost, the minimization of environmental impact measured with ReCiPe and PEF LCA methods, and the maximization of a population density-based indicator are applied as economic, environmental and social sustainability goals, respectively. The augmented $\varepsilon$-constraint method is the selected solution approach. As for the second case-study, it is focused on an electronic components supply chain and includes both forward and reverse flows. The selected sustainability goals are the maximization of profit, minimization of environmental impact (through the ReCiPe method), and the maximization of a GDP-based socio-economic indicator. Given the computational complexity the solution approach to obtain solutions of compromise was based on the optimization of the social objective function with the profit decrease limitations, that is, with profit acting as a constraint. 
Table 1 - Summary of the case-studies presented in this section.

\begin{tabular}{|c|c|c|c|}
\hline & & Case-study I & Case-study II \\
\hline \multicolumn{2}{|l|}{ Industry } & Food retail & Eletronic components \\
\hline \multicolumn{2}{|c|}{ Problem Boundaries } & Forward supply chain & Closed-loop supply chain \\
\hline \multirow{3}{*}{$\begin{array}{l}\text { Sustainability } \\
\text { Goals/Concerns }\end{array}$} & Economic & Minimize cost & Maximize profit \\
\hline & Environmental & $\begin{array}{l}\text { Minimize environmental } \\
\text { impact (ReCiPe and PEF) }\end{array}$ & $\begin{array}{l}\text { Minimize environmental impact } \\
(\mathrm{ReCiPe})\end{array}$ \\
\hline & Social & $\begin{array}{l}\text { Maximize socio-economic } \\
\text { equity (population density } \\
\text { based-indicator) }\end{array}$ & $\begin{array}{l}\text { Maximize socio-economic } \\
\text { equity (GDP based-indicator) }\end{array}$ \\
\hline \multicolumn{2}{|l|}{ Solution approach } & $\begin{array}{l}\text { Augmented } \varepsilon \text {-constraint } \\
\text { method }\end{array}$ & $\begin{array}{l}\text { Socio-economic Objective } \\
\text { Optimization with Economic } \\
\text { and Environmental constraints }\end{array}$ \\
\hline
\end{tabular}

\subsection{Case-study I}

\section{Problem Boundaries/Data}

This case study focuses on a food retail company, in its forward supply chain(Mota et al., 2015a). Its supply chain structure is presented in Figure 4. Products are sent from suppliers to distribution centres where two main supply systems take place: stock and Just-in-Time (JIT). The first one is reserved for non-perishable and frozen products, whereas perishable and some non-perishable products are handled using the latter one. Five different products categories are defined given its different handling and storage conditions: non-perishable products handled using the stock system; frozen products, fruits and vegetables, fresh products, and non-perishable products handled using the JIT system. To each type of product corresponds a different warehouse, according to the described handling and storage conditions. These warehouses are centralized in distribution centres, as shown in Figure 4. From the distribution centres the products are sent to stores.

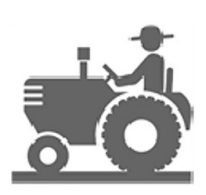

Suppliers

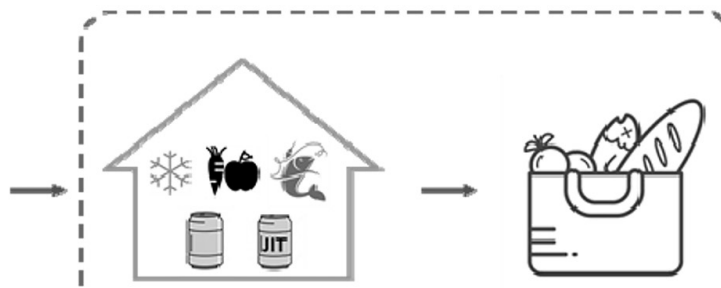

Stores

Distribution centres and warehouses

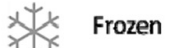

Fruits and vegetables

Fresh

Nonperishable (stock)

Nonperishable (JIT)

Figure 4 - Supply chain structure and identified boundaries. 
The referred company committed itself to promoting sustainable distribution and consumption practices. This way, coupled with the need to optimize their current supply chain, the company decided to include sustainability concerns in the decision process.

\section{Decision variables}

The desired outputs of this work were the determination of the location and capacity (areas) of the warehouses and corresponding distribution centers, as well as the flow of products, that is, the aggregated supply planning occurring between the considered entities. Four decision variables were then considered accordingly. Two binary variables: $Y_{i m}$, which equals 1 if warehouse $i$ with product $m$ is opened/served, 0 otherwise; $K_{i}$, which equals 1 if distribution center $i$ is opened/served, 0 otherwise. Two continuous variables: $A_{m i}$, which returns the area of the warehouse for product $m$ located in $i$, and $X_{m i j t}$, which returns the flow of product m between entity $i$ to entity $j$, at time $t$.

\section{Main constraints}

The problem was subject to distribution constraints, through which it is defined that the demand needs to be satisfied; flow constraints which guarantee the occurrence of flows only between facilities that are opened; warehouse constraints, which assure that the warehouse size is adjusted to the flow going through it, and assign minimum installation areas; and distribution center constraints through which it is assured that a distribution center is opened whenever a warehouse is installed in that same location.

\section{Objective functions}

In this problem, all sustainability concerns were considered as objective functions. Three objective functions were defined:

- Economic objective function: given that no investment decisions are considered in this problem and that all demand is to be satisfied, total supply chain cost is an appropriate economic performance metric. Equation 1 depicts the different components included in this function:

- Fixed warehouse costs $\left(c_{i}^{f}\right)$ controlled by the binary variable $Y_{i}$.

- Fixed distribution center costs $\left(c_{i}^{d f}\right)$ controlled by the binary variable $K_{i}$.

- Variable warehouse costs according to the area that is installed $\left(A_{i}\right)$ and the cost per $\mathrm{m} 2\left(c_{i}^{w}\right)$.

- Transportation costs, according to the cost per kilometer, per product unit, from entity $i$ to entity $j\left(c_{m i j}^{t}\right)$, times the distance between each pair of entities $\left(d_{i j}\right)$ and the flow between entities $\left(X_{m i j t}\right)$. 
- Human resources costs, which result from opening warehouses and/or distribution centers, and are given by the fixed worker cost per warehouse $\left(c_{i}^{\alpha} \alpha_{i}\right.$, e.g. administrative and management positions), the variable workers cost, since the number of workers varies with the installed area $\left(c_{i}^{\beta} \beta_{i}\right.$, e.g. picking and shipping positions), and the cost of workers per distribution center $\left(c_{i}^{\gamma} \gamma_{i}\right.$, e.g. positions in daycare and canteen facilities).

$$
\begin{gathered}
\text { Cost }=\sum_{i \in I_{w}} \sum_{m \in M} c_{i}^{f} Y_{i m}+\sum_{i \in I_{w}} c_{i}^{d f} K_{i}+\sum_{i \in I_{w}} c_{i}^{w} A_{m i}+\sum_{m \in M} \sum_{(i, j) \in A} \sum_{t \in T} c_{m i j}^{t} d_{i j} X_{m i j t} \\
+\sum_{i \in I_{w}} \sum_{m \in M}\left(c_{i}^{\alpha} \alpha_{i} Y_{i m}+c_{i}^{\beta} \beta_{i} A_{m i}\right)+\sum_{i \in I_{w}} c_{i}^{\gamma} \gamma_{i} K_{i}
\end{gathered}
$$

- Environmental objective function: In this work a comparison between two environmental impact assessment methods was performed: ReCiPe 2008 (Goedkoop et al., 2009) and PEF (European Commission, 2013). The considered functional unit is the identified supply chain, meaning that a Life Cycle Analysis is performed on the transportation modes and facilities existent within the defined boundaries of the supply chain being studied. The Ecoinvent database accessed through SimaPro 7.3.2 software was used to environmental impact results, $I_{a c}$ (at the characterization and midpoint levels), for each of the considered activities, $a$, using the ReCiPe 2008 and the PEF methodologies. Equation 2 depicts the environmental objective function which includes the environmental impact of transportation and facility installation, normalized using the reference values indicated by $\eta_{c}$, as shown in equation 2 .

$$
\text { NormEnvImpact }=\sum_{c} \eta_{c}\left(\sum_{m \in M} \sum_{(i, j) \in A} \sum_{t \in T} I_{c} d_{i j} X_{m i j t}+\sum_{i \in I} I_{i c} A_{m i}\right)
$$

- Social objective function: The social objective function is given through equation 3. $\alpha_{i}$ and $\beta_{i}$ represent the fixed and the variable (per m2) number of jobs created at the warehouses, respectively. $\gamma_{i}$ is the number of jobs created at the distribution centers. $\mu_{i}$ corresponds to a regional/country-dependent factor, which can take different values depending on the context of the study. The goal is to prefer job creation in regions/countries with given socio-economic needs, in a way that increases socio-economic equity. For this case-study, given that the geographical boundary was the country of Portugal, the regional factor $\left(\mu_{i}\right)$ selected was based on population density statistics, with the goal of studying the potential impact of governmental economic incentives in relocating facilities to less populated regions.

$$
\text { SocialBenefit }=\sum_{i \in I_{w}} \sum_{m \in M} \mu_{i}\left(\alpha_{i} Y_{i m}+\beta_{i} A_{m i}\right)+\sum_{i \in I_{w}} \mu_{i} \gamma_{i} K_{i}
$$




\section{Solution approach}

Having three conflicting sustainability objectives, a multi-objective approach based on the augmented $\varepsilon$-constraint method (Mavrotas, 2009) was applied. For more detailed information on the implementation of this method within this context see Mota et al. (2015b).

\section{Main outcomes}

Three scenarios were then considered, each corresponding to the optimization of each objective function:

- Scenario 1: minimizing cost;

- Scenario 2: minimizing environmental impact;

- Scenario 3: maximizing social benefit.

Table 2 - Summary of obtained results.

\begin{tabular}{|c|c|c|c|c|c|c|c|}
\hline \multirow{5}{*}{ 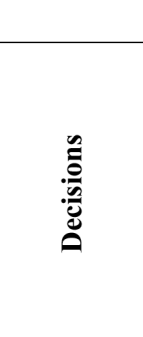 } & \multirow{5}{*}{$\begin{array}{c}\text { Network } \\
\text { configuration }\end{array}$} & \multicolumn{2}{|c|}{ Scenario 1} & \multicolumn{2}{|c|}{ Scenario 2} & \multicolumn{2}{|c|}{ Scenario 3} \\
\hline & & \multirow{2}{*}{$\begin{array}{l}\text { Maia } \\
\text { Viseu }\end{array}$} & \multirow{2}{*}{ 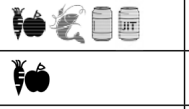 } & \multirow{2}{*}{$\begin{array}{l}\text { Maia } \\
\text { Viseu }\end{array}$} & \multirow{2}{*}{ 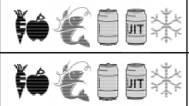 } & Silves & \multirow[t]{2}{*}{ 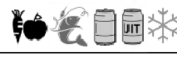 } \\
\hline & & & & & & & \\
\hline & & $\begin{array}{l}\text { Vila } \\
\text { Franca } \\
\text { de Xira }\end{array}$ & 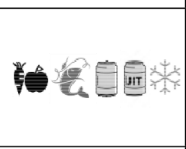 & $\begin{array}{l}\text { Vila } \\
\text { Franca } \\
\text { de } \\
\text { Xira }\end{array}$ & 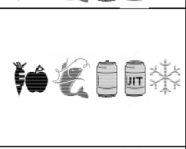 & & \\
\hline & & Faro & 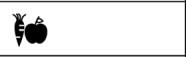 & Faro & 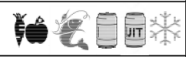 & & \\
\hline \multirow{5}{*}{ 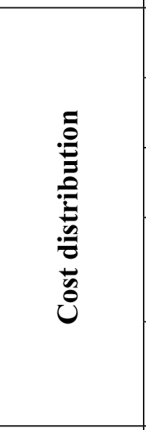 } & $\begin{array}{c}\text { Transportation } \\
(\mathbf{x 1 0} €)\end{array}$ & & 542.2 & & 538.9 & & 3825.3 \\
\hline & $\begin{array}{l}\text { Human resources } \\
\left(\times 10^{7} €\right)\end{array}$ & & 123.3 & & 124.7 & & 121 \\
\hline & $\begin{array}{c}\text { Warehouse fixed } \\
\text { costs }\left(\mathbf{x 1 0}^{7} \epsilon\right)\end{array}$ & & 14.3 & & 26 & & 6.5 \\
\hline & $\begin{array}{c}\text { Warehouse } \\
\text { variable costs } \\
\left(\mathbf{x 1 0}^{7} €\right) \\
\end{array}$ & & 1.9 & & 1.9 & & 1.9 \\
\hline & $\begin{array}{l}\text { Distribution } \\
\text { center costs } \\
\left(\mathbf{x 1 0}^{7} €\right) \\
\end{array}$ & & 19.6 & & 19.6 & & 4.9 \\
\hline \multirow{2}{*}{ 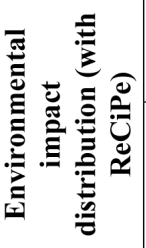 } & $\begin{array}{l}\text { Transportation } \\
\quad\left(\times 10^{3}\right)\end{array}$ & & 6867.4 & & 6725.5 & & 48451.9 \\
\hline & Facilities $\left(\mathbf{x 1 0 ^ { 3 } )}\right.$ & & 750.7 & & 750.7 & & 750.5 \\
\hline
\end{tabular}

Both scenarios S1 and S2 result in the same number and location of DCs. However, the warehouse distribution in each of the DCs is different, as shown in Table 2. The minimum cost 
solution (scenario S1) results from a compromise between transportation and warehouse costs. In scenario S2, by increasing the number of warehouses in each DC, transportation is reduced thus reducing the environmental impact of this solution. In scenario S3 only one distribution center is installed, located in Silves, the less populated region among the initial superstructure. All products flow through this DC so as to assign all workers to this location, with the objective to stimulate the economy in this region. However, these results is a significant increase in cost (by $465 \%$ from scenario S1), namely due to increased transportation costs. Consequently, the environmental impact of this solution is also significantly higher (by 549\% from scenario S2).

It is clear that the solution obtained in scenario $\mathrm{S} 3$ is not a viable one in terms of costs and in terms of logistic activities. It then becomes important to evaluate solutions of compromise between the three scenarios. Through the implementation of the augmented $\varepsilon$-constraint method, the efficient frontier between the three sustainability objectives was drawn, as shown in Figure 5.

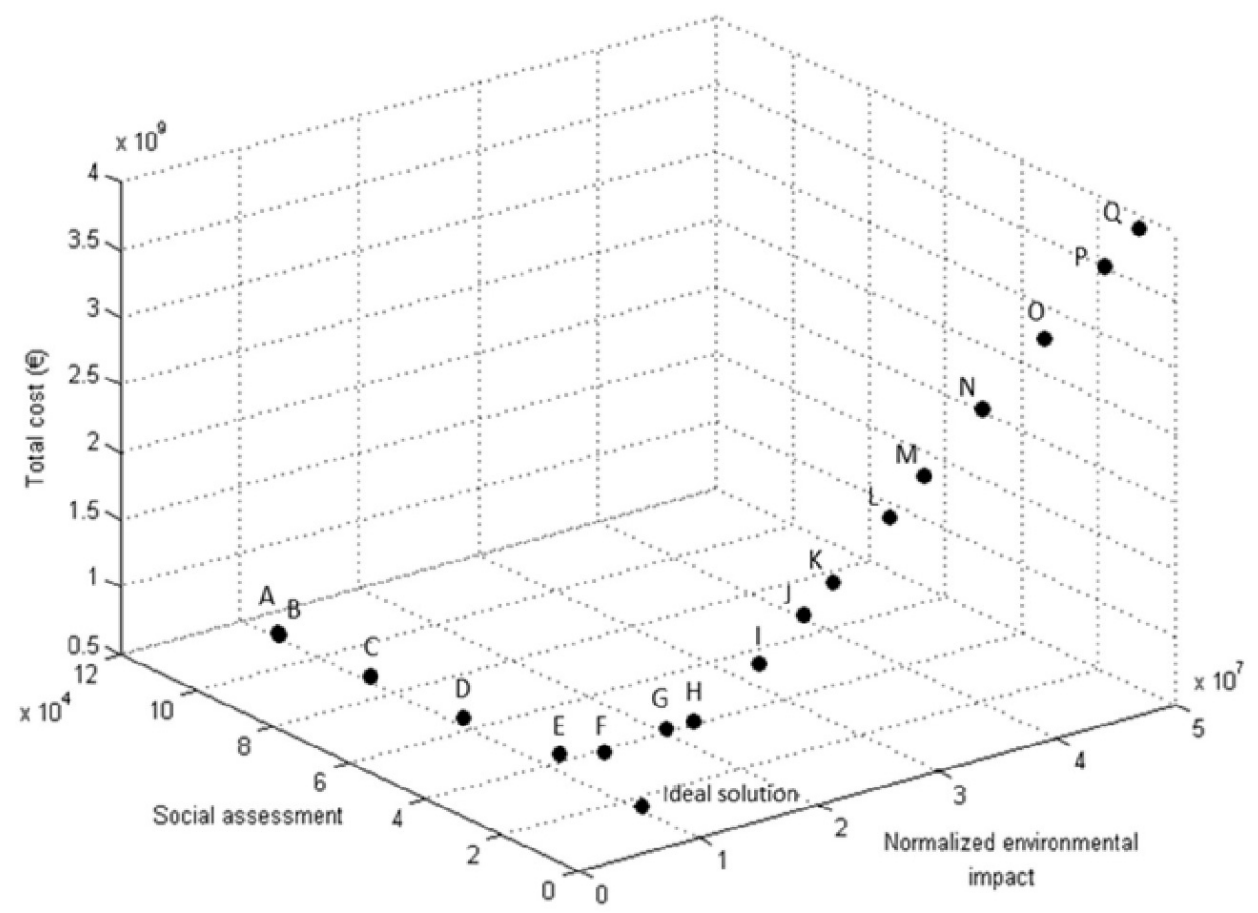

Figure 5 - Multi-objective approach for the minimization of cost with social benefit and environmental impact limitation measured through ReCiPe. Source: (Mota et al., 2015a).

Solutions F and G are the closest to the "ideal solution" obtained from plotting the values of minimum cost, minimum environmental impact and maximum social benefit. These would therefore represent viable and more sustainable solutions, obtainable with a smaller compromise in the economic performance of the supply chain. However, in terms of overall sustainability, none of these solutions is better than the other. The selection of one solution over the other would always have to be based on different weights attributed to the different sustainability pillars. However, 
this solution approach is very helpful to understand what exactly are the trade-offs among the different objectives and what incremental changes could be performed in the supply chain, so as to move towards a more sustainable one.

Another issue analysed with this case-study is related with the different environmental impact indicators, namely, different LCA methods, and the impact they may have on supply chain design and planning decisions. This way, scenario S2 was repeated using PEF instead of ReCiPe. The same exact network was obtained with both methods. However, two outcomes were different:

- the distribution of environmental impact among the different supply chain activities;

- the distribution of the main impacting environmental impact categories.

Through ReCiPe, $90 \%$ of the total environmental impact is a result of transportation activities. Through PEF this number arises to $99.9 \%$. Through ReCiPe, the environmental impact midpoint category Natural Land Transformation is the main source of concern in this supply chain, whereas through PEF the main source is the Freshwater Ecotoxicity environmental impact category. These results can significantly influence investment decisions taken towards minimizing environmental impact which can end up being based on incorrect assumptions. It is then important to clarify and thoroughly investigate the sources of these differences.

\subsection{Case-study II}

\section{Problem Boundaries/Data}

This case study focuses on an electronic components supply chain (Mota et al., 2018). The considered structure is presented in Figure 6, representing a closed-loop supply chain. Raw materials are sent from suppliers to factories where the final products are produced. The final products can then be sent directly to the markets or to intermediate storage points, the warehouses. In turn, the end-of-life product can be sent directly from the markets to the factories or, again, to an intermediate storage point, the warehouses. The distribution between these entities can be performed by unimodal or intermodal transportation (road, sea or air transportation).

Four potential new clients led to the need to evaluate different expansion possibilities, since the existent supply chain did not have enough installed capacity to meet the expected demand. Following European Commission's objective to promote projects with environmental and social added value, the company's decision makers were interested in evaluating the range of possibilities for the design and planning of a new supply chain.

\section{Decision variables}

The desired decision outputs of this work were: 
- at the strategic level: the determination of the number, location and capacities of factories and warehouses, the selection of manufacturing and remanufacturing technologies, and the selection of transportation modes for the distribution between all pairs of entities;

- at the tactical level: the establishment of aggregate production and remanufacturing planning, distribution planning, inventory planning, product recovery strategy and supply planning (that is, how much to source from which supplier).

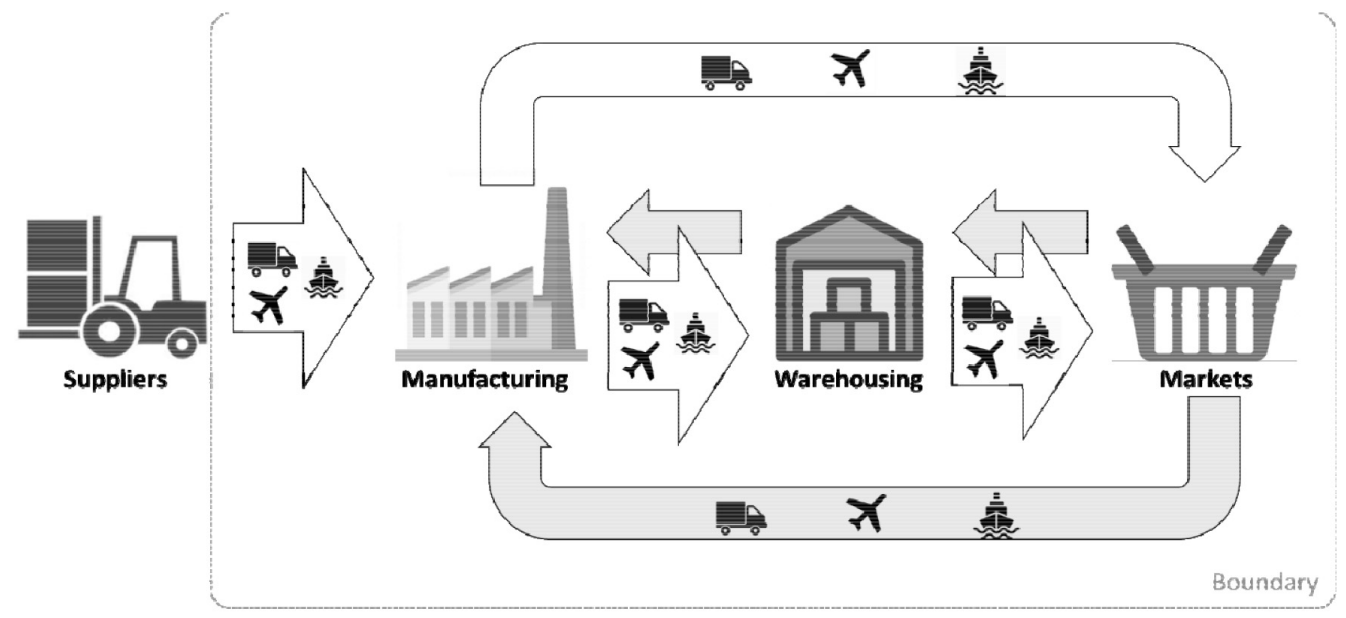

Figure 6 - Supply Chain Structure and Analysis Boundary.

The following decision variables were then defined:

- Continuous variables:

$S_{\text {mit }} \quad$ Inventory of product $m$ in entity $i$ in time period $t$

$P_{m g i t} \quad$ Quantity of product $m$ manufactured with technology $g$ at entity $i$ in time period $t$

$R_{m g i t} \quad$ Quantity of product $m$ remanufactured with technology $g$ at entity $i$ in time period $t$

$X_{\text {maijt }} \quad$ Quantity of product $m$ distributed using transport mode $a$ from entity $i$ to $j$ in time period $t$

$Y C_{i} \quad$ Capacity of entity $i$

- Integer variables:

$K_{a i} \quad$ Number of transportation modes $a$ allocated to entity $i$

$Q_{a i j t} \quad$ Number of trips with transportation mode $a$ between entities $i$ and $j$ in time period $t$

- Binary variables:

$Y_{i} \quad=1$ if entity $i$ is installed

$Z_{g m i}=1$ if technology $g$ that produces product $m$ is installed in entity $i$ 


\section{Main constraints}

The problem was subject to the following constraints:

- material balances: at the factories, at the warehouses, at the airports (transhipment), at the seaports (transhipment), demand and product return constraints;

- entity capacity constraints: related with flow capacity constraints and inventory capacity constraints according to product rotation;

- transportation constraints: transhipment constraints at the airports and seaports, contracted capacity constraints, quantification of the necessary number of transportation modes, maximum investment in transportation modes constraints;

- technology constraints: manufacturing/remanufacturing capacity constraints, minimum production levels, factory-technology allocation constraints;

- sustainability/legislation constraints: maximum working hours constraint, applied to road transportation.

\section{Objective functions}

In this problem, in addition to the sustainability/legislation constraint indicated previously, there are also sustainability goals, translated through three sustainability objective functions: one for the economic performance of the supply chain, one for the environmental performance and one for the social performance.

Regarding the economic objective function, since investment decisions are included in the problem formulation (investment in the construction of factories and warehouses, investment in production technologies, and investment in transportation modes), it is important to select an economic metric that takes them into account. In this case study, the Net Present Value (NPV) was selected. The following costs are considered: raw material costs, production operating costs, product recovery costs, remanufacturing operating costs, transportation costs (insourced and outsourced transportation), inventory costs, and labour costs. The depreciation of the capital invested in each of the investment types previously described is also included.

As for the environmental objective function, the ReCiPe method is applied, as in the previous case-study. However, in this work the environmental impact of the different manufacturing technologies and the different transportation modes are additionally included. Hence, three main environmental impact categories were defined as shown in equation 4 :

- production and remanufacturing, where the environmental impact of the products produced or remanufactured through technology $g\left(I_{m g c}\right)$ is multiplied by the weight of product $m\left(p w_{m}\right)$ and by the quantity produced $\left(P_{m g i t}\right)$ or remanufactured $\left(R_{m g i t}\right)$, 
- transportation, where the environmental impact of products transported with transportation mode $a\left(I_{a c}\right)$ is multiplied by the weight of the product, by the distance travelled $\left(d_{i j}\right)$ and by the product flow $\left(X_{\text {maijt }}\right)$, and

- entity installation, where the environmental impact of entity $i$ installed $\left(I_{i c}\right)$ is multiplied by the installed area $\left(Y C_{i}\right)$.

$$
\begin{aligned}
\text { EnvImpact }= & \sum_{c} \eta_{c}\left(\sum_{\substack{t \in T, i \in I_{f} \\
(m, g) \in H}} I_{m g c} p w_{m}\left(P_{m g i t}+R_{m g i t}\right)\right. \\
& \left.+\sum_{\substack{t \in T \\
(a, m, i, j) \in N e t P}} I_{a c} p w_{m} d_{i j} X_{m a i j t}+\sum_{i \in I_{f} \cup I_{w}} I_{i c} Y C_{i}\right)
\end{aligned}
$$

Regarding the social objective function, given the more global geographical boundaries (compared to the previous case-study, which was based on a single country) and the mostly European context, Gross Domestic Product (GDP) was selected as the socio-economic metric. This way, the social objective function stimulates the supply chain entities and activities to be located in regions with lower GDP.

$$
\begin{aligned}
G D P \text { Ind }= & \sum_{i \in I_{f} \cup I_{w}} \mu_{i}^{G D P} w_{i} Y_{i}+\sum_{i \in I_{f} \cup I_{w}} \mu_{i}^{G D P} w p s q_{i} Y C_{i}+\sum_{\substack{(m, g) \in H \\
i \in I_{f}}} \mu_{i}^{G D P} w_{g} Z_{g m i} \\
& +\sum_{\substack{(a, i, j) \in \text { Net } \\
a \in A_{\text {truck }}}} \mu_{i}^{G D P} w_{a} K_{a i}+\sum_{\substack{(a, m, i, j) \in \text { Net } \\
a \in A_{\text {plane }} \cup A_{\text {ship }} \\
t \in T}} \mu_{i}^{G D P} \frac{w_{a}}{y t h} \cdot p w_{m} \cdot d_{i j} \cdot X_{\text {maijt }}
\end{aligned}
$$

From equation 5, one can see that this objective function also takes into account the impact of three activities, which directly contribute to the creation of jobs, aligned with the boundaries defined for the environmental impact assessment:

- Entity installation, where the fixed and variable number of jobs created in each location, $w_{i}$ and $w p s q$ respectively, are multiplied by the binary variable that controls which facilities are installed $\left(Y_{i}\right)$ and by the continuous variable which controls the installed capacity $\left(Y C_{i}\right)$;

- Technology installation, where the number of jobs created through each installed technology, $w_{g}$, is multiplied by the binary variable which defines which technologies are installed $\left(Z_{g m i}\right)$;

- Transportation, where the number of workers per transportation mode $\left(w_{a}\right)$ in the company's fleet and the number of jobs created through outsourced transportation activities through air or sea transportation are multiplied by the number of transportation modes to acquire $\left(K_{a i}\right)$ and by the flow of products $\left(X_{\text {maijt }}\right)$, respectively. 
$\mu_{i}^{G D P}$ represents a regional factor based on GDP statistics which is lower for regions with higher GDP, higher for regions with lower GDP, since this objective function is to be maximized.

\section{Solution approach}

Given the computational complexity of this case-study the augmented epsilon constraint method was not possible to implement encompassing the three objectives. The followed solution approach was then to analyse, in addition to the three base solutions corresponding to the optimization of each objective function separately, two other solutions of compromise described next. All in all five scenarios were created:

- A: solution with the best economic performance;

- B: solution with the best environmental performance;

- $\mathrm{C}$ and D: solutions that provide the best social performance with a maximum of a 5\% and $15 \%$ reduction in the NPV determined in scenario A, respectively. These are obtained through the maximization of the socio-economic objective function, with an additional constraint stating that the NPV must be at least $95 \%$, for scenario C, and $85 \%$, for scenario $\mathrm{D}$, of the profit obtained in scenario A;

- E: solution with the best social performance.

\section{Main outcomes}

Overall it was possible to conclude that different optimization objectives result in significantly different strategic and tactical decisions. Moreover, attention was brought to the importance of an integrated approach, that is, an approach that considers both strategic and tactical decisions at the different levels of the supply chain simultaneously. This approach permits a better performance level across the supply chain and across the sustainability pillars since there are more degrees of freedom in terms available pool of possible decisions. For instance, in the presented case study, the choice of manufacturing/remanufacturing technologies conditions procurement, transportation options (due to product weight and dimensions) and product recovery options (due to remanufacturing capacities and product characteristics). If one was not including the reverse flow in the analysis, for example, it would not be possible to take into account the impact of manufacturing technology selection in the entire reverse supply chain (that is, in product recovery strategies and remanufacturing technology selection, for example). This work and the application of ToBLoOM also allowed the identification of environmental sustainability hotspots and the definition of strategies to mitigate these negative environmental impacts. In this case-study, manufacturing/remanufacturing activities were identified as the most impacting ones, followed by transportation and finally by facility installation. Investment in projects that lower the costs and environmental impact of remanufacturing technologies were identified as important as they would also allow an improvement in the social performance of the supply chain. Intermodal transportation was also concluded to be beneficial and an important improvement point. Along 
the value chain of the products, product development towards the reduction of weight was also identified as an important step (particularly for one of the product types) towards an improvement in both the environmental and economic performances.

The socio-economic performance evaluation approach allowed to quantify the investment required to improve socio-economic equity through the relocation of supply chain activities. The obtained results are useful for instance for governmental decision makers in funding allocation decisions as well as for corporate decision makers in negotiating relocation activities.

Finally this case-study also allowed to reach important conclusions related to product recovery policies. It was concluded that, under capacity and investment constraints, product recovery policies need to be adjusted to product characteristics (for instance, product dimensions or weight) since these have a direct impact on both transportation activities and on the required factory/warehouse capacity installation. This result again showed the importance of an integrated approach as well as the importance of these types of methodologies in the definition of product recovery strategies.

\section{CONCLUSIONS}

Sustainable Supply Chains are today fundamental systems to support companies' activities adjoining sustainability. In this paper, such systems have been characterised and a set of associated research challenges identified, where the need of developing a sound methodology to address sustainability within supply chains was recognised. It was also concluded that the inherent complexity of such systems calls for the usage of quantitative decision tools that can comprehensively support decision makers. This paper explores this challenge and presents a generic framework, SusFrame, to support practitioners and/or researchers in the development of optimisation based tools for the design and planning of sustainable supply chains. ToBLoOM has been described in this work as a good example of an optimization-based tool, created from the application of SusFrame. ToBLoOM allows the definition of sustainable supply chains by determining simultaneously the supply chain network and the associated planning decisions, while assuring a solution of compromise that accounts for the three sustainability objectives: economic, environmental and social. Two case-studies were solved and the results discussed showing the applicability of SusFrame to help the sustainable supply chain decision process.

Nonetheless addressing the sustainable supply chain through optimization models is still far from being a solved research challenge. Much more should be done where the SusFrame framework can be taken as basis. Firstly, uncertainty and risk modelling need to be adequately incorporated in the optimisation models. Also, at the strategic level the dynamic nature of supply chains ought to be explored. Furthermore, expanding the supply chain decision levels from strategic to tactical and operational decisions is yet to be addressed and consequently additional models are mandatory. Likewise, sustainability modelling requires a deeper formalization and the identification of rigorous indicators on the environmental and social aspects must be pursued. Finally, as the complexity of sustainable supply chain problems easily results in computational intractable problems, efficient solution methods should be targeted. 


\section{ACKNOWLEDGMENTS}

The authors acknowledge the support provided by FCT and P2020 under the project PTDC/EGEOGE/28071/2017, Lisboa -01.0145-Feder-28071.

\section{REFERENCES}

[1] AbBASi M \& NiLSSON F. 2012. Themes and challenges in making supply chains environmentally sustainable. Supply Chain Management: An International Journal, 17: 517-530.

[2] Barbosa-Povoa AP. 2014. Process Supply Chains Management - Where are We? Where to Go Next? Process and Energy Systems Engineering, 2: 23.

[3] Barbosa-Póvoa AP, da Silva C \& Carvalho A. 2018. Opportunities and challenges in sustainable supply chain: An operations research perspective. European Journal of Operational Research, 268: 399-431.

[4] Benoît C, Norris Ga, Valdivia S, Ciroth A, Moberg A, Bos U, Prakash S, Ugaya C \& BECK T. 2010. The guidelines for social life cycle assessment of products: just in time! The International Journal of Life Cycle Assessment, 15: 156-163.

[5] AbBasi M \& NiLSSON F. 2012. Themes and challenges in making supply chains environmentally sustainable. Supply Chain Management: An International Journal, 17: 517-530.

[6] Barbosa-Povoa AP. 2014. Process Supply Chains Management - Where are We? Where to Go Next? Process and Energy Systems Engineering, 2: 23.

[7] Barbosa-Póvoa AP, da Silva C \& CARvalho A. 2018. Opportunities and challenges in sustainable supply chain: An operations research perspective. European Journal of Operational Research, 268: $399-431$.

[8] Benoît C, Norris Ga, Valdivia S, Ciroth A, Moberg A, Bos U, Prakash S, Ugaya C \& BECK T. 2010. The guidelines for social life cycle assessment of products: just in time! The International Journal of Life Cycle Assessment, 15: 156-163.

[9] Bojarski AD, LAÍNEZ JM, Espuña A \& PUigJaner L. 2009. Incorporating environmental impacts and regulations in a holistic supply chains modeling: An LCA approach. Computers \& Chemical Engineering, 33: 1747-1759.

[10] Brandenburg M, Govindan K, Sarkis J \& Seuring S. 2014. Quantitative models for sustainable supply chain management: Developments and directions. European Journal of Operational Research, 233: 299-312.

[11] Cardoso SR, Barbosa-Póvoa APF \& Relvas S. 2013. Design and planning of supply chains with integration of reverse logistics activities under demand uncertainty. European Journal of Operational Research, 226: 436-451.

[12] CARTER CR \& LiANE EASTON P. 2011. Sustainable supply chain management: evolution and future directions. International Journal of Physical Distribution \& Logistics Management, 41: 46-62.

[13] Carvalho A, Mimoso AF, Mendes AN \& Matos HA. 2014. From a literature review to a framework for environmental process impact assessment index. Journal of Cleaner Production, 64: $36-62$.

[14] Chambane A, Ramudhin A \& Paquet M. 2012. Design of sustainable supply chains under the emission trading scheme. International Journal of Production Economics, 135: 37-49.

[15] Christopher M. 2012. Logistics and supply chain management. Pearson UK. 
[16] Ciroth A \& Franze J. 2011. LCA of an ecolabeled notebook: consideration of social and environmental impacts along the entire life cycle. Lulu. com.

[17] Dekner R, Bloemhof J \& Mallidis I. 2012. Operations Research for green logistics - An overview of aspects, issues, contributions and challenges. European Journal of Operational Research, 219: 671-679.

[18] DekKer R \& Fleischmann M. 2004. Reverse logistics: quantitative models for closed-loop supply chains. Springer.

[19] Dreyer L, Hauschild M \& Schierbeck J. 2006. A framework for social life cycle impact assessment (10 pp). The International Journal of Life Cycle Assessment, 11: 88-97.

[20] Duque J, Barbosa-Póvoa APFD \& Novais AQ. 2010. Design and Planning of Sustainable Industrial Networks: Application to a Recovery Network of Residual Products. Industrial \& Engineering Chemistry Research, 49: 4230-4248.

[21] Elsayed K \& PATON D. 2005. The impact of environmental performance on firm performance: static and dynamic panel data evidence. Structural change and economic dynamics, 16: 395-412.

[22] European Commission. 2010. Joint Research Centre - Institute for Environment and Sustainability: International Reference Life Cycle Data System (ILCD) Handbook. Analysis of existing Environmental Impact Assessment methodologies for use in Life Cycle Assessment.

[23] European Commission. 2011. Joint Research Centre - Institute for Environment and Sustainability: International Reference Life Cycle Data System (ILCD) Handbook. Recommendations for Life Cycle Impact Assessment in the European context.

[24] European Commission. 2013. Commission Reconmmendation of 9 April 2013 on the use of common methods to measure and communicate the life cycle environmental performance of products and organisations.

[25] Fleischmann M, Bloemhof-Ruwahd JM, Dekker R, Van der laan E, Van Nunen JA \& VAN WASSENHOVE LN. 1997. Quantitative models for reverse logistics: a review. European Journal of Operational research, 103: 1-17.

[26] Fleischmann M, Beullens P, Bloemhof-Ruwaard JM \& Wassenhove LN. 2001. The impact of product recovery on logistics network design. Production and operations management, 10: $156-173$.

[27] Goedkoop M, Heijungs R, Huijbregts M, Schryver Ad, Struijs J \& Van Zelm R. 2009. ReCiPe 2008 - A life cycle impact assessment method which comprises harmonised category indicators at the midpoint and the endpoint level. The Hague: Ministry of VROM.

[28] Gold S, Seuring S \& Beske P. 2010. Sustainable supply chain management and interorganizational resources: a literature review. Corporate Social Responsibility and Environmental Management, 17: 230-245.

[29] Govindan K, Soleimani H \& Kannan D. 2015. Reverse logistics and closed-loop supply chain: A comprehensive review to explore the future. European Journal of Operational Research, 240: 603-626.

[30] Guillén-Gosálbez G \& Grossmann IE. 2009. Optimal design and planning of sustainable chemical supply chains under uncertainty. AIChE Journal, 55: 99-121.

[31] Hugo A \& Pistikopoulos EN. 2005. Environmentally conscious long-range planning and design of supply chain networks. Journal of Cleaner Production, 13: 1471-1491.

[32] Hunkeler D. 2006. Societal LCA methodology and case study (12 pp). The International Journal of Life Cycle Assessment, 11: 371-382. 
[33] Hutchins MJ \& Sutherland JW. 2008. An exploration of measures of social sustainability and their application to supply chain decisions. Journal of Cleaner Production, 16: 1688-1698.

[34] ILGIN MA \& GUPTA SM. 2010. Environmentally conscious manufacturing and product recovery (ECMPRO): a review of the state of the art. Journal of environmental management, 91: 563-591.

[35] Jørgensen A, Le Bocq A, NaZarkina L \& Hauschild M. 2008. Methodologies for social life cycle assessment. The international journal of life cycle assessment, 13: 96-103.

[36] Labuschagne C, BRent AC \& VAN ERCK RPG. 2005. Assessing the sustainability performances of industries. Journal of Cleaner Production, 13: 373-385.

[37] Mavrotas G. 2009. Effective implementation of the e-constraint method in multi-objective mathematical programming problems. Applied Mathematics and Computation, 213: 455-465.

[38] Meckenstock J, Barbosa-Póvoa AP \& Carvalho A. 2016. The wicked character of sustainable supply chain management: evidence from sustainability reports. Business strategy and the environment, 25: 449-477.

[39] Mota B, Carvalho A, Gomes Mi \& Barbosa-Póvoa AP. 2015a. Design and Planning of Sustainable Supply Chains, Sustainability of Products, Processes and Supply Chains: Theory and Applications. Computer-Aided Chemical Engineering, pp. 333-353.

[40] Mota B, Gomes Mi, Carvalho A \& Barbosa-Povoa AP. 2015b. Towards supply chain sustainability: economic, environmental and social design and planning. Journal of Cleaner Production, 105: 14-27.

[41] Mota B, Gomes Mi, Carvalho A \& Barbosa-Povoa AP. 2018. Sustainable supply chains: an integrated modelling approach under uncertainty. Omega, 77: 32-57.

[42] Nidumolu R, Prahalad CK \& Rangaswami MR. 2009. Why sustainability is now the key driver of innovation. Harvard business review, 87: 56-64.

[43] Paksoy T, Bektas T \& Özceylan E. 2011. Operational and environmental performance measures in a multi-product closed-loop supply chain. Transportation Research Part E: Logistics and Transportation Review, 47: 532-546.

[44] Pinto-Varela T, Barbosa-Póvoa APF \& Novais AQ. 2011. Bi-objective optimization approach to the design and planning of supply chains: economic versus environmental performances. Computers \& Chemical Engineering, 35: 1454-1468.

[45] Salema Mig, Barbosa-Povoa AP \& Novais AQ. 2007. An optimization model for the design of a capacitated multi-product reverse logistics network with uncertainty. European Journal of Operational Research, 179: 1063-1077.

[46] Salema Mig, Barbosa-Povoa AP \& Novais AQ. 2010. Simultaneous design and planning of supply chains with reverse flows: a generic modelling framework. European Journal of Operational Research, 203: 336-349.

[47] SEuRing S. 2013. A review of modeling approaches for sustainable supply chain management. Decision Support Systems, 54: 1513-1520.

[48] TANG CS \& ZHOU S. 2012. Research advances in environmentally and socially sustainable operations. European Journal of Operational Research, 223: 585-594.

[49] UNEP-SETAC. 2009. Guidelines for social life cycle assessment of products. United Nations Environment Programme (UNEP) and Society of Environmental Toxicology and Chemistry (SETAC), Belgium. 